\title{
LA INTERPRETACIÓN DEL GÉNERO EN EL VAMPIRO DE LA COLONIA ROMA*
}

\section{John Evar Strid**}

\section{Resumen}

Muchos críticos han considerado las influencias que tuvo Luis Zapata al escribir El vampiro de la colonia Roma (1979), tales como el género picaresco, el naturalismo y el beat norteamericano, pero ninguno ha examinado los enlaces que la novela tiene con la teoría de diferencia sexual. Por esta razón, este ensayo toma los principios desarrollados por Judith Butler en su libro Gender Trouble: Feminism and the Subversion of Identity (1990) y los aplica a la novela de Zapata. Varios aspectos de la novela tienen correspondencia con la teoría de Butler en relación a la característica performativa del género, pues en ella varios personajes interpretan papeles en sus representaciones de género. Esta relación con la teoría de Butler es lógica porque Zapata se inspiró también en la comunidad homosexual cuando escribió la novela, aunque once años antes de las ideas propuestas por la teórica estadounidense.

Palabras clave: literatura mexicana, literatura gay, teoría queer, estudios del género, estudios subalternos.

\section{THE INTERPRETATION OF GENDER IN EL VAMPIRO DE LA COLONIA ROMA}

\begin{abstract}
Different critics have described the many influences that inspired Luis Zapata when he wrote El vampiro de la Colonia Roma (1979), including such literary genres like the Picaresque, Naturalism and the Beat, but none have looked at the connections that the novel has with queer theory. Therefore, this essay takes the principles developed by Judith Butler in her book Gender Trouble: Feminism and the Subversion of Identity (1990) and applies them to Zapata's novel. Many aspects of the novel correspond with Butler's theory, and support her thesis about the performative nature of gender since many characters perform roles in their gender presentation. The close relationship with Butler's theory makes sense because Zapata also took inspiration from the gay community when he wrote the novel, eleven years before the publication of the ideas proposed by the American theoretician.
\end{abstract}

Keywords: Mexican literature, gay literature, queer theory, gender studies, underground studies.

Recibido: 05-03-2016

Aceptado: 27-09-2016

Este artículo se desarrolló en el contexto del seminario "Literatura Mexicana", dictado por el Dr. Brandon Bisby, de la Maestría en Literatura Latinoamericana en la Northeastern Illinois University. El autor agradece, además, las sugerencias y comentarios de Alexis Angulo, Ana Formenta, Javier Mocarquer, Juan de Dios Peña Ortega, Ernesto Reséndiz Oikión y, en particular, de Eloy Merino.

* Estadounidense. Doctor de Lingüística de Northwestern University, Maestría de Literatura Latinoamericana de Northeastern Illinois University, Académico de Northern Illinois University, Illinois, Estados Unidos. jstrid@niu.edu 
Enla literatura postondera mexicana, la novela que Luis Zapata publicó en 1979, El vampiro de la colonia Roma, marca un hito en la cultura del país por su éxito editorial y por su temática homosexual, pues simboliza una primera apertura a esta minoría en la literatura de dicho país. En general, su publicación coincide con una creciente conciencia de esta minoría dentro de México, un cambio de actitudes que permitió en esta época también las primeras manifestaciones civiles y públicas por este grupo (Martínez 227). Hubo antecedentes en las letras mexicanas, de escasa repercusión, como El diario de José Toledo (1964) de Miguel Barbachano Ponce, o el cuento «Los amigos» (1962) de Juan Vicente Melo. Éstas fueron algunas de las primeras obras de tema abiertamente homosexual. Por su posición como uno de los primeros libros de tema gay que además tuvo un importante impacto cultural en México, El vampiro de la colonia Roma tiene rasgos comunes con la teoría sobre la diferencia sexual (queer), una correspondencia que nunca ha sido investigada en la crítica literaria. Hasta ahora varios críticos han comentado los antecedentes literarios de la novela, mientras que otros han tomado conciencia de las implicaciones de la temática homosexual en ella, pero ninguno considera cómo este texto cumple con las distinciones propuestas por la teoría de diferencia sexual que se desarrolló después de la publicación de la novela. Por esta razón, este ensayo propone examinar la novela de Zapata según la perspectiva de la teoría queer, utilizando en particular las ideas propuestas por Judith Butler en su innovador libro Gender Trouble: Feminism and the Subversion of Identity (1990). La correspondencia entre la novela y la teoría posterior surge de la realidad de una comunidad que ambos intentan captar. Por esta razón, la novela de Zapata valida la teoría y, por su parte, la teoría argumentaría que la novela captura la realidad de esta comunidad de diferencia sexual.

Zapata presenta la novela como las confesiones de Adonis García, un prostituto gay de 25 años que narra su vida a un entrevistador desconocido en siete cintas de grabadora, cuyo contenido individual se prefigura en la narración de sus sueños. Lo anterior ha implicado que algunos críticos busquen los antecedentes literarios de El vampiro de la colonia Roma en la tradición picaresca, el movimiento naturalista y en los escritores beat norteamericanos. Por ejemplo, Alicia Covarrubias enseña muy claramente la relación que tiene la novela con la picaresca, utilizando las funciones básicas de ésta descritas por Francisco Carrillo (ctd. en Covarrubias 187). 
Al inicio, Zapata establece su deuda con la literatura picaresca con su selección de epígrafes provenientes de la misma que preceden a varias cintas (El Lazarillo de Tormes, La pícara Justina, El periquillo sarniento, etc.). Además, el argumento sigue el modelo picaresco con el testimonio de un personaje itinerante y desprotegido que en sus viajes pasa bajo el control de varios amos, utilizando sus experiencias para comentar aspectos morales. Según Covarrubias, el personaje de Adonis está «doblemente marginado por su nacimiento y por su sexualidad» (Covarrubias 18687) lo que determina «su conducta ulterior y [...] constituye la primera de las cuatro funciones básicas de la picaresca» (187). También la novela tiene «la segunda función estructural básica de la picaresca», cuando Adonis se mete a pícaro y «se despliega una secuencia del tipo estimulorespuesta entre individuo marginado y sociedad marginadora» (187). La novela cumple también la tercera característica del género cuando el protagonista toma una nueva identidad («Adonis»), marcando el nacimiento del pícaro e iniciando la serie de aventuras que componen el argumento. En su conclusión, la novela se acopla a la cuarta función de la picaresca cuando Adonis se muda de la colonia Roma y sueña con alejarse de su vida en una nave espacial: «un final en que el pícaro deja de serlo se cumple con la misma ambigüedad de los modelos» (188).

Cecilia Salmerón Tellechea (2004) también admite los antecedentes picarescos de El vampiro de la colonia Roma, pero argumenta que la novela tiene otras fuentes, incluyendo el naturalismo y la literatura de la generación beat norteamericana. Salmerón Tellechea sostiene que dos de los epígrafes en el texto provienen de los libros naturalistas, Santa (1903), de Federico Gamboa, y La vida inútil de Pito Pérez (1938), de José Rubén Romero, y que, además, posee otros rasgos naturalistas como la indagación en la responsabilidad en un proceso de «degradación» (75). Para la crítica,

las vetas picaresca y naturalista de la novela de Zapata pueden explicar, hasta cierto punto, la existencia de digresiones de carácter moral (con ciertos tintes de auto-cuestionamiento, arrepentimiento o culpa) que aparecen en la voz de Adonis y que constituyen uno de los pocos rasgos que alejan al $E l$ vampiro... de la poética beat. (75)

En general, propone que la novela de Zapata tiene mucho parentesco con los escritores beat en: la examinación de un personaje marginalizado 
y atrapado en los excesos del sexo, la prostitución y las drogas; el tener una estructura experimental que presenta la novela como grabaciones; $y$, el uso de un lenguaje popular o de una jerga.

Obviamente Zapata se inspiró en varias fuentes cuando escribió El vampiro de la colonia Roma y las indagaciones académicas mencionadas identifican algunos de los antecedentes literarios importantes del libro. Sin embargo, Zapata creó su obra original y precursora a partir de diversas fuentes inspiradoras, que no incluyen solamente tales antecedentes literarios, sino también el contexto de la época en la que escribía y la realidad de la comunidad que describe. Como la novela trata de la sub-cultura homosexual mexicana de los años sesenta y el autor se identifica con esta comunidad, la inspiración de la misma debe también situarse, en gran parte, en eso sustratos. La novela refleja la realidad de esta comunidad y tiene rasgos esenciales del mundo gay mexicano, un ambiente que tiene enlaces con la teoría queer, desarrollada en su mayor parte once años después de la novela, por la filósofa estadounidense Judith Butler, cuyos postulados tienen sus antecedentes en el pensamiento pos-estructuralista de Michel Foucault. Por esta razón, una comparación directa de la novela con las características de esta teoría puede elucidar la relación que la primera tiene con otra inspiración importante del novelista, la comunidad homosexual en México. Y a pesar de que críticos como Bladimir Ruiz (1999) han considerado las implicaciones de la sexualidad en la novela para la sociedad, en estos estudios no se han abordado las similitudes que la novela tiene con la teoría recién mencionada.

Judith Butler, en su celebrado libro de 1990, Gender Trouble: Feminism and the Subversion of Identity, propone una visión posmoderna de género como un acto performativo: «El género es una estilización repetida del cuerpo, un conjunto de actos repetidos a dentro de un marco rígido regulador que se solidifica con el tiempo para crear la aparición de sustancia, de un tipo natural de ser» (la traducción es mía; 45).

Esta teoría del género se inspira en la idea de Foucault desarrollada en su libro Historia de la sexualidad (1978), donde se afirma que la sexualidad no es una característica natural o biológica de la humanidad sino una experiencia que la sociedad construye y la cual posee rasgos históricos y culturales. Butler desarrolla esta idea e incluye el género como otro ejemplo de esta categoría de construcción social. Para ella, el género no 
resulta de una extensión conceptual o cultural del sexo biológico, sino de prácticas lógicas que resultan de la conceptualización de heterosexualidad como la práctica normal en las relaciones humanas. Como argumenta Tasmin Spargo (1999): «La heterosexualidad obligatoria es instalada en género a través de la creación de tabús contra la homosexualidad, dando una coherencia falsa de aparentemente géneros estables unidos al sexo biológico apropiado» (la traducción es mía; 54).

La realidad biológica no dicta la conducta de una persona en su identidad de género. Al contrario, una persona cumple con su identidad a través de su actuación, por medio de la cual acata las normas sociales de género. En general la teoría implica una idea mucho más fluida de este último (y de la identidad en general). En lugar de pertenecer esencialmente a una categoría social como «hombre» o «mujer», un individuo tiene que interpretar el papel de «hombre» o «mujer», realizando una representación de uno de los géneros según los criterios que la sociedad sanciona como conducta adecuada para realizar este estado. Así una persona no es automáticamente hombre o mujer, pero se convierte en «hombre»o «mujer» en cada momento a través de su actuación. Las ideas de Bulter han influido considerablemente en la concepción del género no solo en los estudios queer, sino también en otros campos de investigación, donde se incluyen la lingüística (Bergvall, 1999; Cameron, 1997) y la educación (Hey, 2006; Masuchika Boldt, 1996), por ejemplo.

La teoría de Butler se aplica directamente al personaje principal que Luis Zapata creó once años antes en su novela El vampiro de la colonia Roma, donde éste, Adonis, tiene una representación performativa de su género. Adonis se reconoce como homosexual y describe su atracción sexual por los hombres desde sus primeras memorias, cuando pensaba en hombres mirando fotos de mujeres: «[...]yo veía una vieja y siempre me imaginaba que algún cuate estaba cogiendo con ella ¿no? me los imaginaba cogiendo a los dos ¿verdad? hasta que un día me empezó a interesar más la figura del chavo que estaba cogiéndose a la vieja y ya pensaba más en él» $(21)^{1}$. De hecho, Adonis descubre su sexualidad en su adolescencia y tiene sus primeras tentativas sexuales con un «amiguito»

En estas y otras citas se han mantenido los espacios en blanco del texto original. 
que vive cerca de su casa. Siente contra su cuerpo el pene de su amigo mientras ambos montan en bicicleta y después exploran más: «pero total nos agarramos la verga creo primero él a mí y luego yo a él y 'no que agárrame la verga' y 'no que agárramela tú' y que no sé qué y no sé cuánto pero nunca pasamos de eso ¿verdad? d e agarrarnos la verga por encima del pantalón» (22).

Por esta razón el personaje de Zapata se presenta como hombre, pero toma el papel de uno que ama a otros hombres; lo que, según algunas interpretaciones como la de Ruiz (1999), rompe el binarismo tradicional masculino-femenino, pero crea uno nuevo: heterosexualidad/ homosexualidad (excluyendo bisexualidad); interpretación que coincide con la de Héctor Domínguez-Ruvalcaba (2007): «La novela cuestiona la relación binaria entre lo masculino y lo femenino a través de un viaje arriesgado de aprendizaje sexual... » (la traducción es mía; 139). De hecho, la novela resta importancia a otras distinciones sociales; $y$, si las considera, es para decir que no son importantes en el contexto homosexual. Por ejemplo, cuando Adonis habla de sus experiencias en los baños públicos, nota que todas las clases sociales acuden a los «Baños Ecuador»: «... hay muchísima cooperación entre todos ¿ves? como si todos fueran iguales ahí las clases sociales se la pelan al sexo ¿verdad? y todos cooperando para que todos gocen...» (Zapata 160).

Debido a su sexualidad, la narración de Adonis reconoce muy pocas relaciones con mujeres durante su vida. Incluso su madre no fue muy importante para él: «siempre estuvo enferma siempre desde que yo me acuerdo estaba mal del corazón quién sabe qué tenía desde que tengo memoria la veo acostada en su cama con un tanque de oxígeno al lado» (16). Su madre murió cuando tenía diez años, pero él no sintió mucho: «no le dimos mucha importancia... nos pusimos tristes pero ni siquiera lloramos» (19). En contraste, Adonis amaba a su padre y padeció mucho su fallecimiento: «[...]sí lloré muchísimo me dolió mucho la muerte de mi papá[...]era la única persona que quería y se murió» (25).

Aparte de su madre, Adonis narra relaciones que tuvo con otras tres mujeres: su cuñada en León, la madrina de su hermano y Lilia, la amiga de un «cuate». No tuvo una relación muy cercana con la primera, y de ella solo revela que su medio hermano la maltrataba y que ella transfería el maltrato que le daba su esposo a él: «ya me empezaba a ver feo y a 
me decía con la mirada que [...] me largara sus propios problemas y me daba sopa fría que ya tenía con cuando me daba y un pedecito de carne que me cabía entre dos muelas» (32). En cambio, la relación de Adonis con la segunda era más intensa, pues la buscaba muy seguido después que regresó a la Ciudad de México: «[...] era casi mi madrina ¿no? era muy cuatita» (46). Ella siempre solía regalarle cien pesos y al final le consiguió un trabajo en un periódico. Pero la dejó de ver por vergüenza después de haber renunciado a este trabajo porque prefería talonear (prostituirse en las calles). La última mujer cuya relación narra era Lilia, la amiga de su amigo Carlos, con quien vivió por una temporada. Una vez en ausencia de Carlos, tuvo relaciones sexuales con ella: «así fue como cumplí por única vez con el bello sexo» (90). Pero no parece que le haya gustado mucho y narra que «[...] lo había hecho porque ya sabía que lo iba a ir a decir porque además de fea era muy chismosa pero ya los otros cuates dejaron de chingar con que me la cogiera y yo dejé de sentir estas presiones» (89).

De esta manera, Adonis tiene la gran mayoría de sus relaciones con varones y se define como homosexual. Al principio de la novela él detalla esta división social en un sueño cuando describe a algunos hombres en una fiesta:

$$
\begin{aligned}
& \text { pero se veía que todos eran heterosexuales } \\
& \text { tenían cara de heterosexuales } \\
& \text { decir cómo son las caras de los heterosexuales } \\
& \text { pero uno como homosexual ha te puedo } \\
& \text { en la cara de la gente su ha aprendido a ver } \\
& \text { de cuenta tu no puedes describir una cara de menso } \\
& \text { pero ves alguien en la calle que tiene cara de menso y dices } \\
& \text { "ah pus este buey tiene cara de menso" entons } \\
& \text { así es ¿no? (13) }
\end{aligned}
$$

La división entre homosexuales («gayos») y heterosexuales («bugas») parece estar muy clara para Adonis y es algo que nota en las facciones de alguien desde el primer encuentro.

Al principio cuenta que le molestaba ser diferente e intentaba esconder su secreto de sus amigos heterosexuales:

me sentía diferente yo entonces ni siquiera sabía lo que era homosexualidad, ¿ves? [...] pero sí me sentía mal 
sobre todo porque me chingaban a cada rato con eso si hubiera sabido que la homosexualidad es una cosa de lo más normal ¿no? como pienso ahorita que cada uno tiene derecho a hacer con su vida sexual lo que se le pegue la gana ps no me hubiera sentido tan mal ¿verdad? pero entonces me sacaba mucho de onda sentirme diferente y yo siempre que no era cierto que no me acordaba en fin siempre tratando de taparle el ojo al macho (27)

Aún después que empezó a talonear, tenía amigos heterosexuales con quienes mantenía amistad y se sentía a gusto con ellos, aunque no compartían su identidad como «gayo». Era durante esta temporada que vivía con Carlos, un amigo heterosexual, y se hallaba presionado para cumplir con el sexo opuesto. En esta época Adonis todavía se encontraba confortable con amigos heterosexuales:

yo entonces me sentía muy agusto así entre cuates bugas y esa onda [...] entonces contábamos chistes n o hablábamos a lo mejor por eso se me hacía fácil estar con ellos como que no tenía que decir quién era yo ni lo que pensaba aparte de que yo creo que no pensaba nada nomás pensaba en coger entonces sólo tenía que decir “ ¿ya se saben el de pepito y la maestra?' o cualquier otro y si ellos decían que no pues se les contaba y ya ¿ves? (87)

En esa época pasada con sus amigos heterosexuales, Adonis lograba asimilarse a ellos y por esto se siente presionado para coger con Lilia:

[...] ya sabían mi onda o sea ya sabían que yo taloneaba y veían que llevaba a muchos chavos ahí y que cogía gratis con ellos pero cómo te diré ellos no agarraban la onda de que o sea a pesar de que ya sabían de todos mis desmadres me veían tan parecido a ellos en muchos aspectos en todo el cotorreo que agarrábamos (88)

En esta época Adonis todavía tiene muchas cosas en común con sus amigos heterosexuales, que le permiten vivir con ellos e identificarse como otro amigo regular. El hecho que sus amigos heterosexuales pudieran aceptarlo como un modelo normal (o heterosexual), en esta época, significa que Adonis todavía cumple con las normas sociales de heteronormatividad en su actuación. 
Sin embargo, al final Adonis no puede esconder su identidad homosexual. En varias ocasiones revela que las personas se percatan de su identidad. Por ejemplo, cuando la policía los detiene a él y a ocho amigos del ambiente en un coche, los agentes notan su sexualidad rápidamente. También cuando Adonis y su tercera pareja, Pepe, van a la cárcel, después de tres días los otros presos comienzan a notar su diferencia: «...pero empezaron a así a insinuar ondas, a hacer preguntas entre ellos ¿no? a hacer comentarios 'no si te digo que los agentes me dijeron me soltaron la onda de que les gusta' ¿verdad? pero dirigiéndose a nosotros» (125). Quizás por esta razón, más tarde, describe que comenzaba a sentirse incómodo con los heterosexuales:

[...] siempre que estoy con un buga me pasa lo mismo que con las viejas no se me ocurre de que hablar no sé ni qué onda no es lo mismo que estar con alguien de ambiente no puedes estar diciéndoles "mira qué cuero está ese cuate qué ricas nalgas tiene" porque te mandan al carajo te dicen 'pinche puto' y en un descuido a lo mejor te madrean. (53)

Adonis, el vampiro, divide el mundo entre los «gayos» y los «bugas», $\mathrm{y}$ se identifica como "gayo» $\mathrm{u}$ homosexual. Conserva amistades con heterosexuales por muchos años, pero esconde su identidad ante ellos y al final ya deja de sentirse a gusto con ellos. Por eso termina identificándose con la comunidad homosexual: «la gente de ambiente se entiende era muy curioso porque todo el mundo era cuate de todo el mundo o sea todos se conocían a todos y todos este se protegían se ayudaban era como una gran hermandad gaya» (165).

Sin embargo, en otras ocasiones Adonis declara que la división entre «gayos» $\mathrm{y}$ «bugas» no es tan tajante. Por ejemplo, cuando describe a su hermano como «buga», aunque éste vive con Frenchi, un homosexual, tiene que explicarse: «[...] mi hermano era es buga [...] bueno no buga buga ¿quién es totalmente buga? nadie ¿verdad? cualquiera tiene un pasado que ocultar o por lo menos lo ha soñado lo ha pensado ahora él está casado y tiene dos niños, ¿ves?» (41). Así Adonis abre la puerta a la posibilidad de la bisexualidad o de relaciones homosexuales dentro del mundo heterosexual y a que las personas pueden variar su conducta de género durante sus vidas, un ejemplo de representación variable de aquel que vincula la novela estrechamente con la teoría de Butler. 
Luego, en la novela, cuando habla de la temporada en su vida en la que se encontraba rodeado por heterosexuales, cuenta que éstos tenían en ocasiones conductas que no calzaban con su heterosexualidad:

entons ya te imaginarás que volvió a ser vida de desmadre buga o sea que buga con sus este reservas ya te había dicho que mi hermano había estado viviendo con una loca ¿no? y también uno de esos monos se padroteaba a otra loca que trabajaba en la lotería nacional y había otro que también había tenido su pasado medio mayatón así es que en realidad eran bugas solamente en sus actitudes ¿no? porque eran muy así de "oye cabrón qué pedo" y eso ¿no? y además lo que hacían pues era muy de desmadre buga contar chistes y emborracharse y emborracharse y contar chistes... (112)

Al final la partición inicial de la sociedad que hace Adonis, entre «bugas» y «gayos», no es absoluta, y el hecho de ser heterosexual para él tiene más que ver con la mentalidad y el comportamiento -algo que se corresponde exactamente con el argumento de Butler en Gender Trouble-. Butler (1990) tampoco acepta una interpretación rígida de estas categorías y critica la separación estricta propuesta por Monique Wittig:

[...] la disyunción radical propuesta por Wittig entre la heterosexualidad y la homosexualidad sencillamente no es verdad, que hay estructuras de homosexualidad psíquica adentro de las relaciones heterosexuales y estructuras de heterosexualidad psíquica adentro de la sexualidad y las relaciones gay y lesbiana. (la traducción es mía; 165)

Esencialmente, Butler argumenta que hay elementos homosexuales dentro del mundo heterosexual y viceversa. En su totalidad, la idea de Butler se corresponde precisamente con la idea de Adonis de que el hecho de ser heterosexual se define más por «actitudes» y por la conducta (nosexual).

Otra correspondencia con la teoría de Butler es el hecho de que algunas veces una persona puede cambiar su comportamiento de género, interpretando un papel que normalmente no le pertenece, una interpretación que explica la idea de Adonis al afirmar que su hermano es esencialmente heterosexual aunque compartiera vivienda con Frenchi. 
Adonis relata un incidente cuando intentó convertir a un amigo:

[...] era de esos cuates con los que tienes que hacer labor de convencimiento ¿verdad? desos que se están muriendo porque alguien les meta la verga pero no se atreven a reconocerlo y así era con este chavo tenía que estarle calentando la cabeza con otras ondas y hablarle de viejas y todo eso pero ya iba por buen camino la cosa y es que estaba muy bueno muy bueno si no ni le hubiera hecho la lucha tampoco crees que pertenezco al patronato pro salvación de bugas $[\ldots](78)$

En otras ocasiones Adonis se ha prometido su propia conversión a heterosexual, por ejemplo, cuando contrajo enfermedades venéreas: «[...] cada vez que he tenido gonorrea he jurado y perjurado no volver a meter la verga he odiado encabronadamente a los putos y he prometido volverme buga si salgo de ésta [...]» (57). Con estos ejemplos (y el de su hermano) está claro que Adonis (y Zapata) consideran que la interpretación que una persona hace del género es fluida y que puede variar según las circunstancias, una idea que apoya completamente la teoría de Butler.

Al final el personaje Adonis García se identifica como «gayo», pero según él, el mundo homosexual no es uno monolítico donde no existan divisiones. Por ejemplo, Adonis se declara, uno de «los homosexuales de corazón... los homosexuales serios... los que no tenemos que gritar a los cuatro vientos que somos putos» (41). Adonis contrasta «los homosexuales de corazón» con las «locas»-los homosexuales que son obvios. Cuando distingue entre ambos, usa como ejemplo de loca al novio de su hermano, Frenchi, que era la mujer en la relación y que tenía «su publico que lo iba a ver danzar en mallas» (41). En general, las «locas» son más afeminadas que «los homosexuales de corazón». Adonis en sus comentarios muestra un tono de desprecio hacia aquellas, y hacia sus obvios ademanes, una actitud que incluye elementos de misoginia o de homofobia interiorizada. De hecho, Butler ve en el uso de términos despectivos como «loca» la posible aceptación de «modos en que uno se identifica con la versión del opresor sobre los oprimidos» (la traducción es mía; 166). Butler argumenta que en algunos casos el uso de estos términos puede llevar a la recuperación de un sentido positivo. Pero 
el hecho de que Adonis no se identifica con las «locas», y sumadas sus opiniones negativas sobre las mismas, llevan a concluir que no intenta recuperar el sentido de la palabra.

Durante su narración presenta varias locas, donde incluye a: Frenchi, que vivía con su hermano; a su primer novio, René; y a Coral, otro prostituto del ambiente. Adonis pinta a Frenchi como loca «[...] re feo que bárbaro prieto panzón, y chaparro...»(41). A través deFrenchi, Adonis conoce a su primera pareja, René, quien lo apoda «Adonis»y quien también lo inicia en el sexo y en la prostitución. Adonis describe a René como una persona obviamente homosexual: «nomás bastaba verlo para darse cuenta de que era de ambiente» (44). Por ejemplo, comenta que cuando vivían juntos fue testigo de que a René le gustaba bailar en bikini la música de Beny Moré o Pérez Prado; y añade: «muy joto el rené» (68). En otro ejemplo, Adonis cuenta la historia de cuando un ciego en un autobús empezó a toquetear las nalgas de René al creer que se trataba de una mujer y no cesó hasta que metió la mano en la parte delantera y se dio cuenta de que se las veía con un hombre. Entonces el ciego gritó: «jes hombre! ¡es puto! ¡tiene voz de mujer pero es puto!» (69).

De esta manera, Adonis se distingue de las locas que desprecia por su conducta femenina. En este sentido, el caso más extremo es el de Coral, un prostituto travesti:

[...] se fue volviendo más loca sus ademanes sus poses afeminado hasta que un día se ha de haber dado cuenta de que a él no le interesaba ser homosexual ¿verdad? sino mujer porque es diferente ¿no? tú puedes ser homosexual porque te gustan los chavos no porque quieras ser mujer pero este cuate sí entons un día te digo se empezó a vestir de mujer y a andar así por las calles y ¡no sabe! engañaba a todo el mundo nadie se daba cuenta [...]. (166)

Coral es un ejemplo de una loca que se transforma completamente y al final se presenta como mujer. La representación de su género llega al punto de que pasa por mujer: «[...] era más femenino que cualquier mujer así como las lesbianas son más masculinas que los mismos hombres ¿no? pues él era más femenino que todas ¿verdad? 
más bonita que ninguna [...]» (167). Adonis cuenta la historia de un cliente que compartía el auto con Coral creyendo que era mujer, y lo estuvo tocando hasta que se percató de que era hombre. Entonces, lo desvistió y lo forzó a bajar desnudo del coche, en medio del Zócalo, a las dos de la mañana, aunque luego se compadeció de él y lo dejó subir otra vez. Así Coral se transforma de una manera convincente en una mujer, aunque físicamente permanece varón.

En los casos de las otras locas, no mutan completamente como Coral, pero son obviamente homosexuales y en sus relaciones íntimas toman el papel femenino. Por ejemplo, Adonis describe a Frenchi como la mujer en la convivencia con su hermano: «[...] entonces mi hermano vivía con el tal frenchi y hacían vida de pareja haz de cuenta que mi hermano era el hombre y el otro mono la mujer» (41). En su propia relación con René, Adonis nota quién era el hombre de la casa:

[...] era su marido sin darme cuenta porque el cuate
este pensaba que yo era realmente su marido ¿no? ya
ves la mentalidad de las locas bueno de algunas locas o
sea piensan que pueden encontrar un tipo que no
gustándole los hombres se acueste con ellos ¿ves? por eso te
digo que algunas locas están de atar. (52)

Las locas claramente interpretan el papel de la mujer en sus relaciones, y algunas, como Coral, llegan a transformarse en mujeres en su apariencia. En estos ejemplos se puede ver dos aspectos importantes de la teoría de Butler, a saber, que los miembros del mundo homosexual asumen papeles asociados con el hombre o la mujer en una relación heterosexual, lo que indica que existen elementos heterosexuales en el mundo homosexual, y también que las personas desarrollan un papel.

En particular el carácter performativo del género se destaca cuando un hombre se transforma en mujer: "Al imitar al género, los travestís implícitamente revelan la estructura imitativa del género en sí así como su contingencia» (la traducción es mía; 187). El hecho de que las locas interpreten el papel de una mujer, revela claramente el aspecto de actuación del género que existe en El vampiro de la colonia Roma. En esta veta, Adonis se distingue de las locas-lo que significa que la representación de género que él interpreta no es uno femenino sino masculino (el de un hombre)-. Aunque su identidad incluya su atracción física hacia los 
hombres, lo que significa que se define como un homosexual masculino. Esta identidad afecta la manera de su representación y Adonis, como las locas, muestra su identidad homosexual al mundo. Así, cuando él busca tratamiento sicológico, el especialista le dice:

si quieres que yo te atienda pues mira por principio de cuentas esas greñas que traes te las vas a cortar [...] a mí me vas a venir a ver con el pelo corto bien corto y esos zapatos que tienes de llanta de jipi horribles detestables ésos no los vas a traer nunca y nada de esas pulseritas y eso colgajos y demás mariconerías [...]. (150)

Como las locas, Adonis interpreta un papel en su representación de género, lo que señaliza al público su identidad homosexual por el uso de su pelo largo, sus zapatos llamativos y sus adornos.

Existe otro ingrediente importante en la interpretación de género en el mundo homosexual, que se relaciona con la representación que las personas homosexuales desarrollan ante el público. Además de experimentar una variación en su identidad masculina/femenina, los miembros de la minoría homosexual masculina se distinguen por sus roles en la intimidad: en la comunidad homosexual masculina existe la división entre «activos» $\mathrm{y}$ «pasivos». La novela indica que las locas son generalmente pasivas. Por esta razón, Adonis cree que Frenchi era pasivo en la relación con su hermano: «yo me figuro que era nomás pasivo ¿verdad? que nomás mi hermano se lo cogía...» (41). Igualmente René, que interpretaba el papel de mujer en su relación con Adonis, también tomaba la posición pasiva en la cama: «René nomás era pasivo... nunca quiso ser activo» (52). En general, Adonis se describe como un amante que tiende al papel activo; por ejemplo, en la narración de su experiencia como prostituto, normalmente él toma el papel de activo: «le di su piquete así de rápido» (48). El hecho de que Adonis generalmente describa a sus clientes como pasivos, lleva a Balderston y Maristany (2005) a argumentar que Adonis los «feminiza», no obstante el poder económico de éstos. Aun así, Adonis no descarta el papel pasivo y admite que puede cambiar su rol según los gustos del cliente: «además yo cumplo con ellos metiéndoles la verga o dejándomela meter

según sus gustos ¿no crees?» (48). Adonis ilustra su preferencia en la cama cuando, a Zabaleta, un cliente rico que se convierte en su segunda pareja, le confiesa: «[...] que a mí no me gustaba ser pasivo que no 
sentía nada

que nunca había sentido nada» (77), una confesión que anima a Zabaleta a darle «la cogida de su vida» (61). Zabaleta intenta rozar su próstata en todas las posiciones posibles pero Adonis afirma que «no sient[e] nada nomás un dolor de la chingada» (77). Más allá de esta sesión, Adonis no habla de su papel en las relaciones sexuales con Zabaleta o de otra experiencia pasiva, pero el lector puede imaginar que a Zabaleta le gustaba también el papel pasivo pues tenía consoladores por todos lados en su casa, según Adonis.

Otros aspectos de sus relaciones con Zabaleta parecen muy desiguales. Está el hecho de la holgada posición económica de Zabaleta mientras Adonis vive en la casa de éste y además recibe su ayuda monetaria. Adonis no se refiere al papel que él adoptaba en la relación (de marido o de mujer), y por esta razón el lector puede pensar que esta distinción no era importante en su relación. Tampoco parece importante su rol en la relación con su tercer novio, Pepe, ya que Adonis no revela nada de las interioridades de esta convivencia -no ya en la intimidad, ni tampoco en la rutina diaria doméstica-. Cuando está hablando de su vida con Pepe, se enfoca más en la parranda y en el consumo de alcohol, marihuana y estupefacientes.

En conclusión, Zapata tiene varias fuentes inspiradoras cuando escribe El vampiro de la colonia Roma, lo que incluye antecedentes literarios tales como el género picaresco, el naturalismo y las obras de los escritores beat norteamericanos, del modo que lo han descrito varios críticos literarios anteriores. Pero otra fuente fundamental para el autor fue el ambiente social que la novela pinta: la comunidad homosexual en México. Por esta razón, su novela refleja características de un ámbito social particular que Judith Butler teoriza once años después, sin referirse por supuesto a la situación específica de México, en su libro Gender Trouble: Feminism and the Subversion of Identity. Como en la teoría de Butler, El vampiro de la colonia Roma, representa el género de una manera novedosa y los personajes no siguen los papeles tradicionales asignados a ellos por la sociedad mexicana. En lugar de examinar el mundo con un punto de vista que acepte la heteronormatividad, Zapata propone un mundo divido entre heterosexuales y homosexuales, donde esta distinción no siempre está clara. Además, en la sección homosexual de la sociedad existen varias divisiones: entre «locas» y «homosexuales de corazón»y también entre «activos»y «pasivos». Las locas enseñan explícitamente 
el carácter performativo del género, porque toman el papel de mujer en sus relaciones y a veces se convierten en mujeres o travestis. Adonis García se distingue de las locas y las desprecia un poco, un desdén que lleva a Bladimir Ruiz a argumentar que Adonis sufre de una forma de «misoginia desplazada» (Butler 333). Según esta interpretación, Adonis queda marcado por el machismo tradicional mexicano, hasta el punto de que desestima todo lo que tenga alguna característica femenina, incluyendo a las locas. Por esta razón, prefiere representarse como hombre, aprovechando las ventajas de la masculinidad en la sociedad, pero no quiere desempeñar el papel tradicional heterosexual y machista del varón en la sociedad mexicana. Debido a esto, su representación del género revela mucho sobre el papel del machismo en la sociedad mexicana, como argumenta Oscar López: «Adonis despoja las máscaras recubridoras del machismo de la sociedad mexicana, máscaras que, al descubrirlas, le hace factible llegar a la autorreconciliación e incluso el medrar» (77). Además sus opiniones negativas hacia las locas o hacia los miembros más afeminados de la comunidad homosexual enseñan que el vampiro lleva dentro el remanente de su homofobia. La narración de Adonis en El vampiro de la colonia Roma ilustra manifiestamente el carácter performativo del género en la teoría de Butler, donde Adonis García, el vampiro de la Colonia Roma, escoge un papel masculino, pero no tradicional, donde el género se define por su distinción con lo femenino en el marco de la homosexualidad. El hecho de que la novela tenga tanta correspondencia con una teoría que Butler desarrolla una década después de la publicación de El vampiro de la Colonia Roma, indica que Luis Zapata realiza una fiel representación de la comunidad homosexual que le inspira.

\section{Referencias bibliográficas}

Balderston, Daniel and José Maristany. «The lesbian and gay novel in Latin América». The Cambridge Companion to the Latin American Novel. Ed. Efraín Kristal. Cambridge, Cambridge UP, 2005, pp. 200-218.

Bergvall, Victoria L. «Toward a comprehensive theory of language and gender». Language in Society, no. 28, 1999, pp. 273-293. 
Butler, Judith. Gender Trouble: Feminism and the Subversion of Identity. Second Edition. New York, Routledge, 1990.

Covarrubias, Alicia. «El vampiro de la colonia Roma, de Luis Zapata: La nueva picaresca y el reportaje ficticio». Revista de Crítica Literaria Latinoamericana, vol. 20, no. 39, 1994, pp. 183-197.

Cameron, Deborah. «Performing gender identity: Young men's talk and the construction of heterosexual masculinity». Language and masculinity. Eds. Sally Johnson and Ulrike Anna Meinhof. Oxford, Blackwell, 1997, pp. 47-64.

Domínguez-Ruvalcaba, Héctor. Modernity and the Nation in Mexican Representations of Masculinity: From Sensuality to Bloodshed. New York, Palgrave Macmillan, 2007.

Foucault, Michel. The History of Sexuality. New York, Random House, 1978.

Hey, Valerie. «The politics of performative resignification: translating Judith Butler's theoretical discourse and its potential for a sociology of education.». British Journal of Sociology of Education, vol. 4 , no. 27,2006 , pp. 439-457.

López, Oscar. «El vampiro de la colonia Roma: o del travestismo posmoderno». Revista de Literatura Mexicana Contemporánea, vol. 4, no. 10, 1999, pp. 72-78.

Masuchika Boldt, Gail, «Sexist and Heterosexist Responses to Gender Bending in an Elementary Classroom». Curriculum Inquiry, vol. 26, no. 2, 1996, pp. 113-131.

Martínez, José Luis. La literatura mexicana del siglo XX. México, D.F., Consejo Nacional para la Cultura y las Artes, 1995.

Ruiz, Bladimir. «Prostitución y homosexualidad: interpelaciones desde el margen en El vampiro de la colonia Roma de Luis Zapata». Revista Iberoamericana, vol. 65, no. 187, 1999, pp. 327-339.

Salmerón Tellechea, Cecilia. «La Generación Beat como correlato de El vampiro de la colonia Roma.» Revista de Literatura Mexicana Contemporánea, vol.10, no. 24, 2004, pp. 73-84.

Spargo, Tamsin. Foucault and Queer Theory. New York, Totem Books, 1999. 
Zapata, Luis. El vampiro de la colonia Roma: las aventuras, desventuras y sueños de Adonis García. México, D.F., Grijalbo, 1979. 